\title{
Randomised double masked trial comparing the efficacy and tolerance of $0.05 \%$ mequitazine eye drops versus $0.05 \%$ levocabastine and placebo in allergic conjunctivitis induced by a conjunctival provocation test with Dermatophagoides pteronyssinus
}

\author{
B Mortemousque, A Jacquet, C Richard, F Depont, J Colin, N Moore
}

Aim: A double masked randomised trial comparing $0.05 \%$ mequitazine eye drops with $0.05 \%$ levocabastine and placebo was carried out in otherwise heathy volunteers allergic to house dust mites (Dermatophagoides pteronyssinus).

Method: Double masked, randomised, single centre study, comparing three parallel treatment groups. 60 healthy adults with a confirmed history of allergic conjunctivitis to house dust mites for at least 2 years were included and completed the trial. Conjunctival provocation tests (CPT) were done at screening, at visit 2 (V2) (1 week later), and at visit 3 (V3) ( 2 weeks after V2). Treatment was instilled in the same eye, 5 minutes after the CPT at V2, and twice daily until V3. CPT were scored 5, 10, 15, and 60 minutes after instillation of the dose of Dermatophagoides pteronyssinus antigen determined at inclusion (V2, curative test) or resulting in positivity (V3, preventive test)

Results: In the V2 (curative) test the difference between the active treatments and placebo on the redness+itching scores was not significant. At the V3 (preventive) CPT there was a lower number of reactions at the threshold dose with mequitazine $(20 \%)$ compared to placebo $(60 \%, p=0.01)$ or levocabastine (45\%, $p=0.10)$.

Conclusion: This trial failed to clearly demonstrate curative superiority of topical antihistamines with placebo, when a single dose of treatment was instilled following CPT. However mequitazine $0.05 \%$ eye drops were superior to placebo in preventing a reaction to CPT, after 2 weeks of treatment.

\footnotetext{
$\Lambda$ ntihistamine $\mathrm{H}_{1}$ blockers are a common first line treatment of allergic conjunctivitis, ${ }^{1}$ thanks to their efficacy and fast onset of action. Though most are administered orally, ${ }^{2}$ some have been developed for ophthalmic use. Levocabastine is a potent, selective, and fast acting reference $\mathrm{H}_{1}$ antagonist, formulated for nasal and ocular administration as a $0.05 \%$ microsuspension. ${ }^{3}$ Mequitazine is another potent $\mathrm{H}_{1}$ selective antihistamine, widely used orally, ${ }^{4}$ recently formulated as $0.05 \%$ ophthalmic solution. Conjunctival provocation tests (CPT) are a sensitive and reproducible model to assess the efficacy of various antiallergic treatments. ${ }^{5}{ }^{6}$ The specific $\mathrm{CPT}^{7}$ uses allergen instillation to trigger the ocular allergic reaction. Four trials tested mequitazine eye drops on grass pollen CPT as a model of
}

seasonal conjunctivitis. Mequitazine was clearly superior to placebo in preventing redness and itching, ${ }^{8}$ significantly superior to $2 \%$ disodium cromoglycate ${ }^{9}$ and $0.1 \%$ dexamethasone, $^{10}$ and was similar to levocabastine in reducing hyperaemia and itching. ${ }^{11}$

However, it seemed interesting to test mequitazine on a model of perennial conjunctivitis. For this purpose, a double masked randomised trial comparing mequitazine eye drops with levocabastine and placebo was carried out in subjects responsive to Dermatophagoides pteronyssinus allergen. The aim of the study was to show the non-inferiority of topical $0.05 \%$ mequitazine compared to $0.05 \%$ levocabastine eye drops and its superiority compared to placebo.

\section{METHOD}

This was a double masked, randomised, single centre study, comparing three parallel treatment groups of healthy volunteers above 18 years of age of either sex, with history of allergic conjunctivitis to house dust mites for at least 2 years confirmed by a positive prick test to Dermatophagoides pteronyssinus and/or specific IgE $\geqslant$ grade 3 (RAST) within the previous 6 months, and by a positive screening CPT to Dermatophagoides pteronyssinus $(<100 \mathrm{RI} / \mathrm{ml})$. At inclusion they were symptom free, and had an otherwise normal ocular examination with corrected far visual acuity $>0.6$ (20/32) and intraocular pressure $<21 \mathrm{~mm} \mathrm{Hg}$. Subjects were not allowed contact lenses, or any other than the trial medication during the study.

All subjects gave informed consent to the study, which was approved by the regional ethics committee (CCPPRB Bordeaux A).

\section{Study design}

Inclusion visit recorded demographic data, medical, ophthalmological, and allergic history, concomitant systemic and ocular medication, and visual acuity and included a complete ocular examination with biomicroscopy, intraocular pressure (IOP) measurement and fundus assessment. CPT confirmed the allergy: increasing concentrations of the antigen (1.2, 3.7, 11,33 , or $100 \mathrm{RI}$ ) were instilled until a positive reaction was elicited, determining the threshold dose to be used in further tests. The allergic reaction score was assessed at 5, 10, 15, and 60 minutes following the challenge. CPT was scored on conjunctival redness, itching, tearing, and chemosis ${ }^{2}$ (table 1 ). The final score was the sum of individual symptom scores. CPT was defined as positive when the total score was at least 5 , with both redness and itching scores at least equal to 2 . One eye was randomly selected for treatment. 
Table 1 Score* for reaction to conjunctival provocation test. Test is judged positive for study if total score is $\geqslant 4$ with positive redness and itching

\begin{tabular}{|c|c|}
\hline Symptoms & Score \\
\hline Redness of conjunctivitis & $\begin{array}{l}0=\text { none } \\
1=\text { slight } \\
2=\text { moderate } \\
3=\text { severe }\end{array}$ \\
\hline Chemosis & $\begin{array}{l}0=\text { none } \\
1=\text { discreet (detectable with slit lamp, } \\
\text { conjunctiva separate from sclera) } \\
2=\text { moderate (clearly visible, conjunctiva } \\
\text { raised in inferior part) } \\
3=\text { severe (swollen conjunctiva) }\end{array}$ \\
\hline Watering & $\begin{array}{l}0=\text { none } \\
1=\text { slight } \\
2=\text { moderate (occasional nasal flow) } \\
3=\text { severe (tears running down cheeks) }\end{array}$ \\
\hline Pruritis (self evaluated) & $\begin{array}{l}0=\text { none } \\
1=\text { slight (occasional tingling sensation) } \\
2=\text { moderate (permanent hindrance but } \\
\text { no need to rub eye) } \\
3=\text { severe (permanent hindrance with } \\
\text { need to rub eye) } \\
\begin{array}{l}4=\text { unbearable pain (compulsive desire to } \\
\text { rub eye) }\end{array}\end{array}$ \\
\hline
\end{tabular}

\section{Visit 2}

One week later at least, the curative effect of the drug was tested: a CPT was performed with the threshold concentration determined at inclusion and evaluated 5 minutes later, immediately followed by a single drop of the study treatment in the selected eye. Scoring was assessed 5, 10, and 55 minutes later $(10,15,60$ minutes after CPT).

Subjects were then instructed to instil one drop twice daily of the study treatment for 2 weeks in the selected eye.

\section{Visit 3}

Following this treatment the preventive effect of the drug was tested with a CPT using increasing doses of allergen starting from the threshold concentration, until a positive reaction was elicited.

\section{Conjunctival provocation test (CPT)}

Before each CPT, redness, itching, biomicroscopy, and fluorescein test were assessed in both eyes. CPT was performed by applying one $30 \mu \mathrm{l}$ drop in each eye in turn of vehicle or increasing doses of allergen. The same randomly selected eye received the allergen and the treatment throughout the study. The other eye received only the vehicle during CPT.

The same batch of standardised extracts of Dermatophagoides pteronyssinus (Stallergenes, Antony, France) was used throughout the study. The vehicle was first given as a negative control in the fellow eye, then the allergen in the selected eye at increasing doses until a positive reaction was obtained, or at the threshold concentration only (visit 2). After all procedures were completed the eye was rinsed with artificial tears as needed. If necessary, one drop of $0.1 \%$ lodoxamide could be used as rescue medication, immediately or if a late phase reaction occurred ${ }^{12}$ within 24 hours.

\section{Treatments}

Twenty subjects were randomised to each treatment group. The treatments $(0.05 \%$ mequitazine, $0.05 \%$ levocabastine, and placebo) were packed in identical $3 \mathrm{ml}$ bottles delivering
$30 \mu \mathrm{l}$ drops. Each subject was instructed to instil one drop of the study treatment into the study eye twice a day from visit 2 to visit 3.

Mequitazine, levocabastine, and placebo eye drops were provided by Chauvin Bausch \& Lomb.

\section{Safety criteria}

Safety criteria were subjective tolerability, intraocular pressure (IOP), number of subjects with at least one adverse or unexpected event occurring during the study, number of adverse or unexpected event(s) per subject.

Tolerability of instillation was graded within 10 minutes following instillation, on a scale of 0 (painful intolerance) to 4 (no intolerance).

IOP was measured after CPT with a Goldmann applanation tonometer mounted on a slit lamp, after a single drop of $0.5 \%$ fluorescein and $0.4 \%$ oxybuprocaine.

\section{Statistical and analytical plans}

This was a three arm non-inferiority study with the study drug mequitazine, the active control drug levocabastine, and a placebo control group.

All analyses were conducted on the intent to treat population (all subjects having at least one treatment dose and with at least one usable item after the instillation of treatment at visit 2). Since all subjects completed the trial without major protocol violation, this was also the per protocol population.

The main objective of the study was the effect of the drugs after the provocation test at visit 2 (curative effect). The main efficacy criterion was the sum of the scores for redness and itching 10 minutes after the instillation of the medication.

Secondary outcome criteria included the reaction symptom scores at visit 2 (curative effect). and at visit 3 (preventive effect). Failure was defined as a positive CPT for the threshold antigen concentration. Allergen dose eliciting positive reaction at visit 3 was evaluated as positive reaction at threshold or at 1, 2, or $>2$ dosage levels above threshold.

The groups were compared for demographic data, medical history, and the initial CPT measures before the first instillation of study treatment. The sample size was calculated to detect a difference of more than 1 between the two treatment groups for the clinical score at visit 2 after the CPT test and instillation of one drop of treatment, with type I error rate $5 \%$, power $80 \%$, the standard deviation 1.3 for a one sided $t$ test.

Statistical tests of superiority were done two sided with an $\alpha$ level of 5\%, using Kruskal-Wallis's non-parametric test, the $\chi^{2}$ test or Fisher's exact test as appropriate. When the global tests were significant the appropriate pairwise tests were applied with $\alpha$ level adjustment using the Bonferroni correction. Statistical testing of non-inferiority of mequitazine versus levocabastine used a one sided Wilcoxon two sample test. The non-inferiority tests had an $\alpha$ level of 0.05 .

Use of rescue medication at visits 2 and 3 were compared by $\chi^{2}$ test.

Other categorical data were compared using $\chi^{2}$ tests, continuous data by non-parametric tests.

The statistical analysis was performed on a PC using SAS version 6.12 for Windows NT.

\section{RESULTS}

Sixty subjects entered the study and all completed the trial without major deviation or missing values. Twenty subjects were randomised to each treatment group. Subject demographics and allergic history are presented in table 2. At least one ocular medication was used by three $(15 \%)$ of the subjects in the placebo group, none in the levocabastine group, and two (10\%) in the mequitazine group. All initial 
Table 2 Subject demographic characteristics, allergic history, and threshold antigen concentration determined at inclusion

\begin{tabular}{|c|c|c|c|c|c|}
\hline & $\begin{array}{l}\text { Placebo } \\
(n=20)\end{array}$ & $\begin{array}{l}\text { Levocabastine } 0.05 \% \\
(n=20)\end{array}$ & $\begin{array}{l}\text { Mequitazine } \\
(\mathrm{n}=20)\end{array}$ & $\begin{array}{l}\text { Overall } \\
(n=60)\end{array}$ & $p$ Value \\
\hline \multicolumn{6}{|l|}{ Age (years) } \\
\hline Mean (SD) & $23.3(4.1)$ & $23.2(3.8)$ & $27.4(10.9)$ & $24.7(7.2)$ & \multirow{3}{*}{$\begin{array}{l}\text { Kruskal-Wallis } \\
0.83 \\
\chi^{2} 0.53\end{array}$} \\
\hline Min-max & $18-33$ & $18-33$ & $18-51$ & $18-51$ & \\
\hline Male sex & $7(35 \%)$ & $7(35 \%)$ & $10(50 \%)$ & $24(40 \%)$ & \\
\hline \multicolumn{6}{|c|}{ Frequency of allergic symptoms, $\mathbf{n}(\%)$} \\
\hline $2-4$ times a year & $0(0 \%)$ & $1(5 \%)$ & $2(10 \%)$ & $3(5 \%)$ & \multirow{3}{*}{$\begin{array}{l}\chi^{2} \\
0.74\end{array}$} \\
\hline $5-7$ times a year & $1(5 \%)$ & $0(0 \%)$ & $0(0 \%)$ & $1(1.67 \%)$ & \\
\hline All year long & $19(95 \%)$ & $19(95 \%)$ & $18(90 \%)$ & $56(93 \%)$ & \\
\hline \multicolumn{6}{|c|}{ Threshold allergen concentration, $n(\%)$} \\
\hline 1.2 & $5(25 \%)$ & $13(65 \%)$ & $9(45 \%)$ & $27(45 \%)$ & \multirow{4}{*}{$\begin{array}{l}\text { Kruskal-Wallis } \\
0.10\end{array}$} \\
\hline 3.7 & $9(45 \%)$ & $4(20 \%)$ & $4(20 \%)$ & $17(28.3 \%)$ & \\
\hline 11 & $4(20 \%)$ & $1(5 \%)$ & $5(25 \%)$ & $10(16.7 \%)$ & \\
\hline 33 & $2(10 \%)$ & $2(10 \%)$ & $2(10 \%)$ & $6(10 \%)$ & \\
\hline
\end{tabular}

eye examinations were normal including IOP (table 3). All subjects had perennial allergic conjunctivitis (table 2); 26 $(43 \%)$ subjects had a previous positive skin test $(57 \%$ had positive test done on enrolment). No statistically significant difference was found between the treatment groups for any of these items.

\section{Conjunctival provocation tests}

The right eye was randomly selected for testing and treatment in 30 of the 60 subjects, equally distributed between the groups.

The threshold concentrations of allergen, which induced positive reaction at inclusion, are presented in table 3 . There was a significantly greater itching score in the future levocabastine group compared to the future placebo group $(p=0.0084)$. As no drug had yet been given at that time, the difference observed had no clinical relevance. No statistically significant difference was found between the three treatment groups for any other scores.

\section{CPT at visit 2 (curative test)}

All subjects had a normal ocular examination before CPT. Five minutes after the instillation of the same concentration of allergen which induced a positive reaction at inclusion, before treatment instillation, there was no statistically significant difference between the three treatment groups (fig 1). The mean score for hyperaemia + itching 10 minutes after treatment instillation was 2.6 (SD 1.4) in the placebo group, 2.3 (1.4) in the levocabastine group, and 2.4 (1.4) in the mequitazine group (NS).

\section{CPT at visit3 (preventive test)}

No statistically significant difference was found between the treatment groups for redness, itching, and redness + itching scores before CPT. One mequitazine subject had a redness graded 1 and one placebo subject had grade 1 itching. Fifty

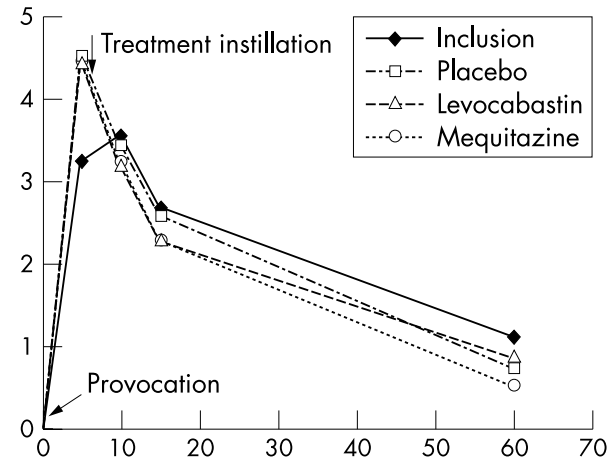

Figure 1 Evolution over time of the mean cumulated redness + itching scores at the inclusion CPT (no treatment, all subjects pooled) and at the second visit (treatment 5 minutes after CPT, 20 subjects per group).

seven $(95 \%)$ of the 60 subjects had a normal pre-CPT slit lamp examination and fluorescein test.

Sixteen of the 20 patients on mequitazine had a negative CPT at the initial threshold antigen concentration, $v$ ll on levocabastine and eight on placebo $(p=0.035)$. In nine patients on mequitazine, the threshold concentration was two or more levels above the baseline threshold, compared with four for levocabastine and three for placebo. Mequitazine was significantly better than placebo $(\mathrm{p}=0.01)$ but not than levocabastine $(\mathrm{p}=0.10)$. Levocabastine was not different from placebo $(p=0.35)$ (table 3 ). Since the antigen concentrations were adjusted to elicit a positive test, there was no significant difference in the final test scores between the three treatment groups.

\section{Drug tolerability}

Tolerability of drug instillation at V2 was judged "excellent" and "good" by respectively 75\% (45/60) and 25\% (15/60) of

Table 3 Change in threshold antigen concentration to induce a positive CPT

\begin{tabular}{llll}
\hline & \multicolumn{2}{l}{ Treatment group } & \\
\cline { 2 - 4 } & Placebo $(\mathbf{n = 2 0 )}$ & Levocabastine $(\mathbf{n}=\mathbf{2 0})$ & Mequitazine $(\mathbf{n}=\mathbf{2 0})$ \\
\hline Positive reaction at: & 12 & 9 & 4 \\
Threshold dose & 5 & 7 & 7 \\
1 level above & 2 & 1 & 7 \\
2 levels above & 1 & 3 & 2 \\
$>2$ levels above & & & \\
\hline
\end{tabular}

Kruskal-Wallis, overall $p=0.0310$; mequitazine $v$ placebo $p=0.01, v$ levocabastine $p=0.10$; levocabastine $v$ placebo $\mathrm{p}=0.35$. 
the subjects, with no difference between the groups. There was no change in IOP during treatment. Late phase reaction within 24 hours following CPT was reported by seven subjects out of 60 following inclusion, 10 subjects after visit 2 (three placebo, four levocabastine, and four mequitazine, $\mathrm{p}=0.14)$ and seven after visit 3 .

Compliance was rated as excellent in 47 out of 60 patients $(78.3 \%)$ and good in the remaining 13.

\section{DISCUSSION}

This study tested the curative and preventive effects of mequitazine compared to levocabastine and placebo in volunteers allergic to house mite antigen. It found mequitazine to be not better than comparators for the curative test but significanty better for prevention. After 2 weeks of treatment, 16 of the 20 patients on mequitazine had a negative CPT at the initial threshold antigen concentration, compared with 11 on levocabastine and eight on placebo. In nine patients on mequitazine, the threshold concentration was two or more levels above the baseline threshold concentration, compared with four for levocabastine and three for placebo.

Because of the difficulties in assessing anti-allergic preparations in the natural setting, because of pollen or antigen counts, intersubject variability and difficulty in field self grading, conjunctival provocation tests (CPT) have become the de facto standard instrument to study allergic conjunctivitis and to measure the effects of drugs. ${ }^{13}$ This safe model allows reproducible quantitative measurement of the allergic response using a well defined grading system. The conjunctival provocation test reproduces the signs and symptoms of allergic conjunctivitis in a controlled setting. ${ }^{46712}$ The signs assessed are those of the allergic reaction, and especially hyperaemia and itching. For the test to be positive both have to be at least grade 2. Chemosis, tearing, and eyelid oedema, even when present, are of more limited significance. The CPT can be judged as the evolution of the scores after a fixed antigen concentration (as in our curative test), or as the antigen concentration needed to elicit a given reaction (as in our prevention test).

Our study had a double objective, assessing the curative effect of the drugs given after the antigenic insult and the preventive effect of repeated instillations, with the main hypothesis of non-inferiority compared to levocabastine. The superiority of the control drug with respect to placebo has already been demonstrated in previous trials. ${ }^{8}$

The evaluation of the curative effect was the main objective of the study. This was assessed on the CPT scores measured 10 minutes after instillation of medication, itself given 5 minutes after the antigen dose determined at inclusion. The results for the two treatment groups were below the placebo values and below the inclusion values, but these scores were in fact quite low in all arms, and not different statistically, making the non-inferiority question between the two active arms moot. The reasons for this failure may be the design of this specific test. This seems to be the first study of the curative effect of antihistamines given post hoc after CPT. At least no other are published. In other studies, ${ }^{14-22}$ the drug is given preventively before the antigen, as in the second part of our study, where mequitazine but not levocabastine was superior to placebo. The itching and redness scores chosen to declare inclusion CPT positive and select the threshold antigen dose for future CPTs may have been too low. The low threshold antigen dose may have resulted in a reaction too mild to clearly discriminate placebo. Subjects with perennial conjunctivitis generally have less marked signs than those with acute allergic conjunctivitis. The primary efficacy criterion was evaluated at least 15 minutes after the CPT which could also at least partially explain the quite low score of hyperaemia + itching. Moreover, the strong placebo effect could be linked to a mechanical rinsing effect washing out the allergens and inducing a rapid relief of signs.

Even though the main criterion was not fulfilled, probably for the reasons given above, the time response curves in figure 1 show a clear tendency for both active ingredients to have a superior effect to placebo, at least at 5 and 10 minutes (fig 1). The results of this part of the study cannot be compared with other published reports, since none used the same methodology.

The evaluation of the capacity of the treatment to prevent CPT reaction was done after 2 weeks of treatment. Significantly more subjects in the mequitazine group than in the placebo group were unresponsive to the threshold dose determined at inclusion. Patients in the levocabastine group were in between, significantly different from either mequitazine or placebo. The preventive effects of mequitazine confirm previous studies using other types of antigens. ${ }^{8}$

In conclusion, this randomised double masked comparative trial of mequitazine $v$ levocabastine or placebo confirmed the preventive effect of 15 days' treatment with mequitazine against house dust mite antigen CPT in allergic subjects. In the curative test, where the drug was given after rather than before the CPT, mequitazine just failed to show a difference with placebo or levocabastine, for a number of possible reasons, mostly methodological. The methodology of curative CPT testing with antihistamines clearly needs to be better defined, including the definition of threshold doses, and the optimal timing of drug instillations and effect measurement.

\section{Authors' affiliations}

B Mortemousque, J Colin, Service d'Ophtalmologie, CHU de Bordeaux, 33076 Bordeaux, France

A Jacquet, F Depont, N Moore, Département de Pharmacologie, CHU de Bordeaux, France

C Richard, Laboratoire Chauvin Bausch \& Lomb, Montpellier, France

Correspondence to: Bruno Mortemousque MD, PhD, Service d'Ophtalmologie, CHU de Bordeaux, 33076 Bordeaux, France; bruno.mortemousque@chu-bordeaux.fr

Accepted for publication 2 July 2003

\section{REFERENCES}

1 Friedlander $\mathrm{MH}$. Conjunctivitis of allergen origin: clinical presentation and differential diagnosis. Surv Ophthalmol 1993;38(suppl): 105-14.

2 Abelson MB, Schaefer K. Conjunctivitis of allergic origin: immunologic mechanisms and current approaches to therapy. Surv Ophthalmol 1993;38(suppl): 115-32.

3 Noble S, McTavish D. Levocabastine. An update of its pharmacology, clinical efficacy and tolerability in the topical treatment of allergic rhinitis and conjunctivitis. Drugs 1995:50:1032-49.

4 Skassa-Brociek W, Bousquet J, Montes F, et al. Double-blind placebocontrolled study of loratadine, mequitazine, and placebo in the symptomatic treatment of seasonal allergic rhinitis. J Allergy Clin Immunol 1988:81:725-30.

5 Abelson MB, Chambers WA, Smith LM. Conjunctival allergen challenge: a clinical approach to studying allergic conjunctivitis. Arch Ophthalmol 1990;108:84-8.

6 Dupin O, Compeyre S, Trinquand C, et al. Intérêt du test de provocation conjonctivale (TPC) dans l'évaluation de l'activité de deux concentrations d'un collyre anti-allergique, la méquitazine. J Fr Ophtalmol 1998;21:12-18.

7 Moller C, Bjorksten B, Nilsson G, et al. The precision of the conjunctival provocation test. Allergy 1984;39:37-41.

8 Persi L, Dupin O, Arnaud B, et al. Efficacy of mequitazine in comparison with placebo assessed by ocular challenge with allergen in allergic conjunctivitis. Allergy 1997;52:451-54

9 Dupin $\mathrm{O}$, Robert F, Trinquand C, et al. Etude comparative de l'efficacité de deux collyres anti-allergiques au cours $d^{\prime} u n$ test de provocation conjonctivale: méquitazine versus cromoglycate de sodium. In: Congrès de la Société Française d'Ophtalmologie-SFO.104. 1998:160.

10 Richard C, Bibas P, Trinquand C. Evaluation of topical $0.05 \%$ mequitazine and $0.05 \%$ levocabastine in comparison with $0.1 \%$ dexamethasone in the allergen challenge model. In: ARVO Annual Meeting. 1999. Fort Lauderdale. Abstract book (abstract 4818). 
11 Trinquand C, Dupin O, Belayachi N, Hoang-Xuan T. Clinical, double masked comparison of mequitazine eyedrops $0.05 \%$ compared to levocabastine eyedrops $0.05 \%$ in allergic conjunctivitis. In: ARVO Annual Meeting. 1999. Fort Lauderdale. Abstract book: (abstract 4819).

12 Bertel F, Mortemousque B, Sicard H, et al. Conjunctival provocation test with Dermatophagoides pteronyssinus in the diagnosis of allergic conjunctivitis from house mites. J Fr Ophtalmol 2001;24:581-9.

13 Friedlaender MH. Conjunctival provocative tests: a model of human ocular allergy. Trans Am Ophthalmol Soc 1989;87:577-97.

14 Spangler DL, Bensch G, Berdy GJ. Evaluation of the efficacy of olopatadine hydrochloride $0.1 \%$ ophthalmic solution and azelastine hydrochloride $0.05 \%$ ophthalmic solution in the conjunctival allergen challenge model. Clin Ther $2001 ; 23: 1272-80$.

15 Friedlaender $\mathrm{MH}$, Harris J, LaVallee $\mathrm{N}$, et al. Evaluation of the onset and duration of effect of azelastine eye drops $(0.05 \%)$ versus placebo in patients with allergic conjunctivitis using an allergen challenge model. Ophthalmology 2000; 107:2152-7.

16 Butrus S, Greiner JV, Discepola M, et al. Comparison of the clinical efficacy and comfort of olopatadine hydrochloride $0.1 \%$ ophthalmic solution and nedocromil sodium $2 \%$ ophthalmic solution in the human conjunctival allergen challenge model. Clin Ther 2000;22:1462-72.
17 Abelson MB, Welch DL. An evaluation of onset and duration of action of patanol (olopatadine hydrochloride ophthalmic solution $0.1 \%$ ) compared to Claritin (loratadine $10 \mathrm{mg}$ ) tablets in acute allergic conjunctivitis in the conjunctival allergen challenge model. Acta Ophthalmol Scand Suppl 2000;230:60-3.

18 Deschenes J, Discepola M, Abelson M. Comparative evaluation of olopatadine ophthalmic solution $(0.1 \%)$ versus ketorolac ophthalmic solution $(0.5 \%)$ using the provocative antigen challenge model. Acta Ophthalmol Scand Suppl 1999;228:47-52.

19 Netland PA, Leahy C, Krenzer KL. Emedastine ophthalmic solution 0.05\% versus levocabastine ophthalmic suspension $0.05 \%$ in the treatment of allergic conjunctivitis using the conjunctival allergen challenge model. Am J Ophthalmol 2000;130:717-23

20 Abelson MB, George MA, Smith LM. Evaluation of $0.05 \%$ levocabastine versus $4 \%$ sodium cromolyn in the allergen challenge model. Ophthalmology $1995 ; 102: 310-6$

21 Abelson MB, George MA, Schaefer K, et al. Evaluation of the new ophthalmic antihistamine, $0.05 \%$ levocabastine, in the clinical allergen challenge model of allergic conjunctivitis. J Allergy Clin Immunol 1994:94(Pt 1):458-64.

22 Rimas M, Kjellman NI, Blychert LO, et al. Topical levocabastine protects better than sodium cromoglycate and placebo in conjunctival provocation tests. Allergy 1990;45:18-21. 